\title{
Social Movement Driven by Interplay of Traditional and Social Media: The Case of HKTV
}

\author{
Wendy Chan Wing Lam* \\ Hong Kong Baptist University, HKSAR, China \\ *Corresponding author. Tel.: 61940966; email: chanwinglamwendy@gmail.com \\ Manuscript submitted August 18, 2014; accepted April 20, 2015. \\ doi: 10.17706/ijcce.2015.4.6.409-416
}

\begin{abstract}
Traditional and social media have been taking prominent role in transmitting the messages worldwide. Online communities gather together to fight for their common goal. Members offer social connection, information and emotion supports. Yet, social media platforms are often characterized as quick and informative. On the other hand, the traditional media, there is always a time lapse in between for printing and publishing. Therefore, this study aims to explore the key factors that contributed by online social media community and social media for the success of the social movement. Altogether there are fourteen local newspapers that were examined, in which the result shows that immediacy and the appealing of social sentiments conjured up by the social media platforms helped to put forward the whole social movement.
\end{abstract}

Key words: Online sharing behavior, social media, social movement, social mobilization.

\section{Introduction}

On Oct. 15th, 2013, Hong Kong government released the final decision that Hong Kong Television Network (HKTV) was not given a free TV license. As this decision conjured up much controversy and noises from the public, both the traditional mass media as well as the social media had an extensive coverage on the issue. However, in the light of motivation of the mass, social media seemed played an influential role, for example, to lead the public to the Causeway Bay demonstration on Oct. $20^{\text {th }}, 2013$. Users took initiative to upload information and the frequent updates in turn motivated the mass. Users relied on social media to follow-up the latest information as reflected from the tremendous feedbacks and interactions. Social media has been developed as an important common platform for exchanges and collective motions.

This Facebook Page, "Over thousands of people support HKTV, please give the TV license to HKTV" (http://www.facebook.com/supporthktv) [1], was created by the public on Oct. 15 , 2013. The administrator aimed to protest against they think the unreasonable act of government to deny giving the free license to Hong Kong Television Network. As stated on the Page, the Page name highlights about the supports from the mass. The administrator expected a few thousands would support the Page by clicking the "Like" button. Later, the number of "Like" exceeded 10,000. Within 6 days, from Oct. 15 $5^{\text {th }}$ Oct. $21^{\text {st, }}$, the page enlisted a total of 495,000 "Like". It dropped to a total of 483,000 after the zenith of the incident. This has been the highest number of "Like" for a Page, as compared with the latest Page named "Scholarism" enlisted over 184,000 "Like" as of 2014.

The rest of this paper is organized as follows. It starts with a review of the research on online media, 
traditional media and social engagement, and identifies the factors that possibly affect users' behavior in participating in social mobilization. The next section describes the methodology on how we collet the data through the social media platform, Facebook as well as locally published newspapers. The third section further reports the findings from the data and explaining how these factors affect the success of social movement. The fourth section discusses the aims of the study and considers how social sites could further enhance users' motivation in participating in the social movement in a prompt manner.

\section{Literature Review}

Previous Research has shown profound interests in how mass media help put forward the social mobilization. While social mobilization is not a new term for the era of Internet, current social events' supports were first found among the online communities. In light of this, social media helps to contribute to the social mobilization power evidently. Social mobilization is defined as, "It is a broad- scale movement to engage people's participation and create a supportive environment in achieving a specific development goal" [2]. The term political engagement is defined as, "Political engagement has traditionally been defined through the concept of the public sphere" [3]. We employ this idea in our case as social mobilization where we could see we use the sphere to discuss what we want to voice out and user generated content becomes a driving force for one to make their voices heard. And it is also very important to notice that, "the internet would allow the public sphere to move in a direction that allowed or richer conversation and a more complex exchange of ideas a public sphere online could be accessible to all citizens" [3]. In fact, the social media plays a prominent role to connect the people together, "Facebook considers its services inherently social and its plugins and buttons are called social plugins we summarize the activities they generate as so-called social activities" [4]. It is also said that information communication technologies has important implications for social mobilizations [5]. This again echoes to our research while we are looking at the issue of protest against the denial of television license of Hong Kong Television. In the prior studies in the local context, it states that, the news media itself should bear the responsibility to urge the government and the society to share their ideas and give solutions to the matters. In the light of the help from the social media as well as traditional mass media, this event arouses much controversy and therefore, our research question is whether user generated content could more effectively mobilize the public against this local issue.

\subsection{Online Media and Social Mobilization}

It is stated in the past researches that "social media has been used to mobilize volunteers to map natural disasters in real-time, to conduct large-scale search-and-rescue missions, and to locate physical objects within extremely short time frames" [6]. Past researchers also believed that, "information and communication technologies are transforming politics" [7], [8]. However, while the prompt spread of information not only contributes to the immediacy on the aid of men power but also shed light on the political environment. On the other hand, "In their framing of issues, activists try to influence public perceptions of which issues are important, which solutions are workable, and why mobilization is worth the trouble" [9]. More than that, the role of social media tends to help pass the messages in which, "Within high volume social media communications, considerable effort is required to persuade people about the importance of a particular message or cause or even to notice it at all" [10]. Often, we found framing in the media, newspapers especially. While we try to motivate the mass, the first thing will be through the information dissemination. People could register a free account through facebook, twitter or other social media platorms. The social movements could be carried out easily by the emotional attachment shared by the users. The political participation has been proved positively interrelated with the use of the social media platforms. "A key issue in political communication is the relationship between patterns of media use, political motivation and political participation. A core assumption is that in a democracy, people should 
follow news and current affairs, be politically interested and participate in political processes" [11]. With more and more youth navigate between the "traditional" and "new" media for civic and political participation, and whether the "traditional/new" dichotomy is of practical and theoretical significance for citizens and researchers [12]. Once again, nowadays, it is no denial that social movement could be carried out with the aid of social media platforms.

\subsection{Traditional Media and Social Engagement}

Newspapers, as classified as the traditional media, their role is to inform the readers about the most up to date news. Though the immediacy of social media platforms have become the edge to carry out the social movement, it is notable to see that newspapers also take a dominant role in motivating the mass. Previous researches showed that, "Old media still populate this landscape as well, from newspapers and other media sources, to public lectures, to leaflets and other ad hoc publications. Even apart from common caveats as to who has access, criteria for evaluation of these new and old media as tools for political change must vary" [13]. This is evident that newspaper still has effect on the social engagement. Also, past researches also showed that, "Several studies have in fact found consistent positive relationships between traditional news media use - such as television news exposure and newspaper reading — and different aspects of political involvement" [14]-[16]. In the 21st century, newspapers are not the only platforms we obtain information, but its effects should not be underestimated. Therefore,

We posited that, Daily Coverage on local newspapers and intense interaction from online social media has been effective to motivate the mass and thus put forward the social movement concerning the case of HKTV.

\section{Methodology}

\subsection{Background}

Social sites such as Facebook, Weibo, Twitter, and blogs, are platforms that allow people to establish their social circle. These platforms are free and open to anyone who registers as a member. Users could create their own profiles, create post or updates, comment on others' post, upload photo or video, etc. As of July 2014, “500 million tweets are sent everyday (Twitter, 2014)". Specifically, as of 2013, there were more than 1.28 billion active users of Facebook. These social media sites have become closely integrated into our lives.

This social movement reached a zenith on Oct. $21^{\text {st }}, 2013$ when a large scale demonstration was held in Causeway Bay way up to Central Government Offices. As reported from South China Morning Post [17], there are altogether tens of thousands of people going on the street as the deny to giving HKTV free license to air is a damage to HK city's core value. As this social mobilization has aroused the public concern for a period of time, therefore, we would like to carry out the research from Oct. $15^{\text {th }}$ to Oct. $31^{\text {st }}$ by looking at both the traditional newspapers and also how social media platforms play a part in the social movement.

The research was measured by Facebook and also local newspapers. For the Facebook, by typing the keywords "Hong Kong Television Network" so as to find out the most welcoming event page. This research focused on the page that enlisted the most supports by people with the evidence of the numbers of likes. By typing in "Hong Kong TV" through Wisenews, limited the coverage on the local context. The newspapers include Apple Daily, Taikung Pao, HKdaily, Sing Tao, The Oriental Daily, The Sun, Sing Pao, Economic Daily News, HK Headline, Metro Daily, Ming Pao, Sky Post, Hong Kong Economic Journal and am730.

\section{Findings}

From Oct. 15th to 31st, 2013, shown in the Tables 1 and 2, it was found that Facebook Page "Over thousands of people support HKTV, please give the TV license to HKTV" had 278 posts, on average, 16 pieces per day. The updated content includes the status, photos, link sharings, event promotions, etc. The 
Facebook users interacted by "Like", "Comments" and "Shares", these three enable them to interact with the users and especially their circles of friends could see they support this page as every post is a public one. Take an example, if they like one post, it would be put onto the top feed. According to our result, there are 27 posts have over 10,000 Likes; for the posts that conjure up 1000 likes, there are altogether 254 which accounts for $91 \%$ of the total postings within 17 days. More than that, for comments that could have over 100 people discussing, there are a total of 102 posts. For the shares, there are a total of 88 posts that could have over 100 people involving. It could be concluded that the interaction is vigorous in the page. It is notable that the top five that resulted in the most Likes are the status with words and photos.

Table 1. Related Facebook Groups and Pages with Keywords “Hong Kong Television” (Retrieved on Oct. 31st, 2013)

\begin{tabular}{lll}
\hline \hline & Names of Related Facebook Pages or Groups & Total Likes \\
\hline 1 & Over thousands of people support HKTV, please & 495,620 \\
2 & give the TV license to HKTV [ Event page] & 213,670 \\
3 & HKTV [Event page] & 5,013 \\
\hline \hline
\end{tabular}

Table 2. Summary of Interactions of Page "Over Thousands of People Support HKTV, Please Give the TV License to HKTV"

\begin{tabular}{llccl}
\hline \hline Interactions & Minimum & Maximum & Postings & $\begin{array}{l}\text { Total } \\
\text { Numbers }\end{array}$ \\
\hline Likes & 200 & 36,346 & Over 10,000 & 26 \\
& & & Over 1,000 & 254 \\
Comments & 2 & 1,899 & Over 100 & 102 \\
Shares & 1 & 3,631 & Over 100 & 88 \\
\hline \hline
\end{tabular}

Table 3. The Top Five Postings of Page "Over Thousands of People Support HKTV, Please Give the TV License to HKTV" (Sorted by "Likes")

\begin{tabular}{lllll}
\hline \hline Date & Contents & Likes & Comments & Shares \\
\hline $15 / 10 / 2013$ & Text, "Facebook has over ten thousands of people to support & 36,346 & 1,200 & 3,631 \\
$15 / 10 / 2013$ & Text, "Please share and support HKTV for the license" & 35,928 & 826 & 1,392 \\
$16 / 10 / 2013$ & Text, "Support HKTV for getting the license" & 29,090 & 1,899 & 1,801 \\
$20 / 10 / 2013$ & Photo, "Artists also support HKTV for getting the license" & 28,380 & 382 & 345 \\
$20 / 10 / 2013$ & Photo \& Text, "Many people went on the street for demonstration" & 23,304 & 289 & 307 \\
\hline \hline
\end{tabular}

Table 4. Wise News Search with the Chinese Keywords "Hong Kong TV" from 2013 Oct. $15^{\text {th }}$ to $31^{\text {st }}$

\begin{tabular}{ll}
\hline Newspaper & Sub-totals \\
\hline Apple Daily & 365 \\
Ming Pao Daily News & 319 \\
Takung Pao & 101 \\
Hong Kong Daily News & 179 \\
Sing Tao Daily & 193 \\
The Headline Daily & 133 \\
Sing Pao & 132 \\
The Sun & 122 \\
AM730 & 122 \\
Oriental Daily News & 111 \\
Hong Kong Economic Times & 89 \\
Sky post & 70 \\
Metro Daily & 69 \\
Hong Kong Commercial Daily & 38 \\
Total & 2,043 \\
\hline \hline
\end{tabular}

Table 3 and Table 5 showed that many of the postings received widely support by the users and Table 4 
showed that Hong Kong TV is also largely covered by the traditional media. By clicking the like button on Facebook, users automatically feed their liking into the News Feed where their friends could filter through their recent activities. This liking gesture is interpreted as a "user-generated linking", which indicates, on the one hand, "an affective response" and on the other hand, user's adding social values to it. Therefore, it is plausible to see "liking" as a sign of users' engagement in this event. From this point of view, the mounting likes from users could be as regarded as gestures of wide on-line support.

Table 5. Postings of Facebook Page "Over Thousands of People Support HKTV, Please Give the TV License to HKTV" That Motivates People to Go for Social Mobilization

\begin{tabular}{|c|c|c|c|c|}
\hline Date & Topic & Comments & Likes & Shares \\
\hline \multirow[t]{6}{*}{$2013 / 10 / 16$} & $\begin{array}{l}\text { Text, "Press conference for demonstration that HKTV is denied to get the } \\
\text { license" }\end{array}$ & 471 & 20887 & 611 \\
\hline & Video, "Unfair government decision" & 80 & 6639 & 85 \\
\hline & $\begin{array}{l}\text { Video, "Ricky Wong Wai-Kay, the chairman of Hong Kong Televsion supports } \\
\text { the act of their employees" }\end{array}$ & 164 & 8569 & 43 \\
\hline & $\begin{array}{l}\text { Video, "The legal process will take a long time, so we should go for the } \\
\text { demonstration first" }\end{array}$ & 165 & 10092 & 100 \\
\hline & Text, “Anyone will go for Sunday demonstration?" & 468 & 8953 & 112 \\
\hline & Photo, "All netizens, please go on the street" & 862 & 20355 & 2492 \\
\hline \multirow[t]{2}{*}{$2013 / 10 / 17$} & $\begin{array}{l}\text { Text \& Link, "Ricky Wong Wai-Kay said he would be calm to face the } \\
\text { difficulty" }\end{array}$ & 80 & 4684 & 17 \\
\hline & Text, "Volunteers needed for the demonstration" & 16 & 2133 & 26 \\
\hline \multirow[t]{4}{*}{$2013 / 10 / 18$} & Text, "HKTV staff encouraged the public to go for the demonstration" & 8 & 384 & 25 \\
\hline & $\begin{array}{l}\text { Photo, "Thanks Apple Daily, go for the demonstration to fight for the license } \\
\text { for HKTV" }\end{array}$ & 32 & 1997 & 27 \\
\hline & Photo, "See you all on Sunday at three at the East Point Road" & 50 & 2018 & 15 \\
\hline & Photo, "The details of the demonstration" & 99 & 8227 & 105 \\
\hline \multirow[t]{6}{*}{$2013 / 10 / 19$} & Text, “Organize the demonstration and come up with slogan” & 6 & 4795 & 69 \\
\hline & Photo, "Demonstration T-shirt" & 41 & 4655 & 43 \\
\hline & Photo \& Text, "Demonstration timetable" & 527 & 8801 & 1473 \\
\hline & Text, "Call for the supports for the demonstration" & 93 & 3827 & 92 \\
\hline & Text, "Call for the supports in Causeway Bay" & 59 & 3310 & 21 \\
\hline & Text, "To voice out our concerns through demonstration" & 153 & 5004 & 64 \\
\hline \multirow[t]{9}{*}{$2013 / 10 / 20$} & $\begin{array}{l}\text { Text, "Over thousands of people support HKTV, please give the TV license to } \\
\text { HKTV" }\end{array}$ & 298 & 7093 & 1432 \\
\hline & Photo, "Many people walking from Central for the demonstration" & 289 & 23304 & 307 \\
\hline & Photo, "The parade at Causeway Bay" & 44 & 3778 & 24 \\
\hline & Photo, "Artists show their supports and said politics has been around us" & 102 & 10204 & 45 \\
\hline & Photo, "Netizens help out on the discipline of the demonstration" & 289 & 13502 & 161 \\
\hline & Text, "Please ask your friends to come to support the demonstration" & 71 & 5602 & 103 \\
\hline & Photo, "Demonstration Tshirt" & 41 & 4655 & 43 \\
\hline & Text, "Show their persistence to surround the headquarter" & 225 & 18334 & 513 \\
\hline & Text, "Surround headquarter" & 351 & 19,782 & 188 \\
\hline
\end{tabular}

\section{Discussion}

\subsection{Traditional Newspapers: Widely Cover the Event}

In these two weeks' time, we focus on local news. The Chinese keywords, "Hong Kong TV" were typed in the WiseSearch and retrieved the news that was related to this keyword daily. In order to shed light in Hong Kong social movement, we only digged out the local newspaper and only choose those are local news. In the search results, we have a total number of news pieces of 2,043. The least coverage appeared on Hong Kong Commercial Daily and the most coverage appeared on Apple Daily.

Furthermore, there are altogether 14 newspapers listed below that have coverage in this particular issue. 
Averagely, each newspaper has around 145 piece of news in these two weeks. And it is crucial to see that the most coverage (365) that the newspaper gets is the Apple Daily which is considered as a radical newspaper with sharp agenda setting, and then the Ming Pao Daily News (319) and the third one is Sing Tao Daily (193). It is rather surprising to see the radical newspapers Oriental Daily News and The Sun have (111) and (122) respectively within these two weeks, ranked seventh and eighth. Therefore, it could be interpreted that these papers may not be as effective as the social media platforms so as to motivate the mass to go on the street.

\subsection{Dominant Role of Social Media: Facebook Act as a More Prominent Role in Social Mobilization than Radical Papers}

On Oct. $20^{\text {th }}, 2013$, a large scale demonstration was held in Central to show public discontentment and opposition to government's decision on the HKTV's application for free license. This demonstration which means besieging the Central Government, has been given frequent concern and grand supports in the Facebook campaign page " Over thousands of people support HKTV, please give the TV license to HKTV " Over thousands of people support HKTV, please give the TV license to HKTV ". As the data displays, there are overall 27 postings from Oct. $15^{\text {th }}$ to $20^{\text {th }}, 2013$ which have explicit information of this parade in a variety of forms such as pictures, videos and articles. Besides, all of the 27 have been liked by at least a thousand users and 8 postings have won 10 thousand likes. All these results have spoken for heated concerns from netizens to this social mobilization.

\subsection{Hong Kong Subtle Identity Is Further Enhanced by the Flow of Information in Facebook Platforms}

Identity construction is a complex issue. However, in this context, most of the people that go for the demonstration are under the crown of "supporting the HKTV against the denial of television license." This is particularly true that the traditional mass media has been seen as a bridge for transmitting the messages. However, sometimes, these media could not carry out the concept of social responsibility with their own stance. Facebook platform could let the people feel the pulse of the demonstration instantly. The power could not be underestimated in which it is emotional appealing to other readers in the Facebook through videos sharings and stars endorsement on the social movement. More importantly, it is said that" [By communicating] with each other, members display their group identity and their personal identity at the same time" [18].

\subsection{Facebook as a "Sharing and Community"}

It is apparent in the findings that interactions between users in Facebook are frequent and intense. By "liking" the campaign page of an event, users could, on one hand, join in a community with others showing the same concern or support; on the other hand, they could get access to information of the event through streamline of postings which they could "like", "comment" or "share". As is noticed in the case of HKTV facebook campaign page, users' comments on certain posting could gain a lot of responses from others and at times this communication could develop into another topic. From this point of view, Facebook serves not only as an alternative source of information, but "also facilitates the widespread exchange of opinions and public discourse" [12]. Facebook, or more precisely, particular event page in Facebook takes on the role of community where users could post, share and communicate with other members. In this HKTV case, this identity is strongly manifested through their slogans, such as "Support HKTV" and "Demonstrate at the Headquarter". These slogans as voice for their mind, also call up users in the community to participate in social mobilization. On the contrary, this sense of community would be difficult to foster by traditional media where the lack of immediacy and the limit of coverage consequently impede effective interactions among users. 


\section{Conclusion}

This research has met its target to give insights to local social mobilization. From the perspective of efficiency, user-oriented platforms such as Facebook serves as a more productive agent than traditional news press in social mobilization. In the case of "Hong Kong Television Network for a free television license was rejected and denied", it was shown that the major campaign page in Facebook alone had contributed 279 postings and updates while 2043 articles were produced by altogether 14 traditional local newspapers.

Along with competitive edge of fast circulation, Facebook in this case has gained grand supports from netizens. By the end of Oct. 31th, "Over thousands of people support HKTV, please give the TV license to HKTV" Campaign page has been "liked" by 495,620 users, and around 91 per cent of all the postings liked by over 1000 users. Those postings, different from the long and detailed articles in newspaper, on most occasions constitute of pictures and texts in short and concise wording.

It well concludes that Facebook as a paradigm of social media could project larger influence in social mobilization than traditional mass media. This change could be partly attributed to its increasing role as "a mainstream, popular culture" with the popularity of computer. Nonetheless, traditional media suffers from limits of setting and editing, losing its edge in the pursuit of fast and instant information. Also, it should be noticed that such user-oriented platform fosters a strong sense of community through sharing, commenting and liking, in the process of which interlinks independent users with similar desire and belief.

Successful as Facebook in this mobilization of HKTV free license, it is still up in the air whether user-generated content would take the place of traditional media in the near future. For the authors, it is deemed that traditional media could join hands with user-generated content instead of being completed edged out of the market. This collaboration would supplement the non-professional part of user's content while remaining its edge on quick response.

\section{Limitation and Further Studies}

This study explores how user-generated content from Facebook help put forward the social event with traditional mass media in social mobilization. As platforms for user-generated content are numerous, the authors choose Facebook, a widely used social media in Hong Kong, as the base to focus on. Inspiring as the result is, it is geographically limited due to the imbalanced development of digital technology as well as difference in political policy and cultural factors. Therefore, the author suggests that the role of user-generated content in social mobilization should be reevaluated in order to gain a more objective understanding in face of current digital divide.

\section{References}

[1] Facebook. (October 15, 2013). Over Thousands of People Support HKTV, Please Give the TV License to HKTV.

[2] Wang, B., Zhan, S., Sun, J., \& Lee, L. (2009). Social mobilization and social marketing to promote NaFeEDTA-fortified soya sauce in an iron-deficient population through a public-private partnership. Public Health Nutrition, 12(10), 1751-1759.

[3] Rontynen, C. I. P. (2011). Social media's influence on political engagement: Examining the use of Facebook \& Twitter in Alberta. Master of Art., University of Calgary.

[4] Gerlitz, C., \& Helmond, A. (January 2011). Hit, link, like and share, organizing the social and the fabric of the web in a like economy. Presented at the DMI Mini-Conference.

[5] McGlinchey, E., \& Johnson, E. (2007). Aiding the internet in central Asia. Democratisation, 14(2), 273-288.

[6] Rutherford, A., Cebrian, M., Dsouza, S., Moro, E., Pentland, A., \& Rahwan, I. (2013). Limits of social 
mobilization. Proceedings of the National Academy of Sciences, 110(16), 6281-6286.

[7] Fung, A., Russon-Gilman, H., \& Shkabatur, J. (2013). Six models for the Internet+ Politics. International Studies Review, 15(1), 30-47.

[8] Ito, M., Baumer, S., Bittanti, M., Cody, R., Herr-Stephenson, B., Horst, H. A., \& Tripp, L. (2010). Hanging out, messing around, and geeking out. Digital Media.

[9] Cooper, A. H. (2002). Media framing and social movement mobilization: German peace protest against INF missiles, the Gulf War, and NATO peace enforcement in Bosnia. European Journal of Political Research, 41(1), 37-80.

[10] Rutherford, A., Cebrian, M., Rahwan, I., Dsouza, S., McInerney, J., Naroditskiy, V., \& Miller, S. U. (2013). Targeted social mobilization in a global manhunt. PloS One, 8(9).

[11] Habermas, J. (1989). The Structural Transformation of the Public Sphere: An Inquiry into a Category of Bourgeois Society. Cambridge, MA: MIT Press.

[12] Skoric, M. M., \& Poor, N. (2013). Youth engagement in Singapore: The interplay of social and traditional media. Journal of Broadcasting \& Electronic Media, 57(2), 187-204.

[13] Weiss, M. L. (2013). Parsing the power of "New Media" in Malaysia. Journal of Contemporary Asia, 43(4), 591-612.

[14] Dimitrova, D. V., Shehata, A., Strömbäck, J., \& Nord, L. W. (2011). The effects of digital media on political knowledge and participation in election campaigns: Evidence from panel data. Communication Research.

[15] Newton, K. (1999). Mass media effects: Mobilization or media malaise? British Journal of Political Science, 29(4), 577-599.

[16] Norris, P. (2000). A Virtuous Circle: Political Communications in Postindustrial Societies. Cambridge: Cambridge University Press.

[17] South China Morning Post. (Oct. 21 $\left.{ }^{\text {st }}, 2013\right)$. Thousands protest to defend Hong Kong's core values after failed HKTV license bid. From http://www.scmp.com/news/hong-kong/article/1336074/thousands-protest-defend-hong-kongs-cor e-values-after-failed-hktv

[18] Giese, K. (2004). Speaker's corner or virtual panopticon: Discursive construction of Chinese identities online. Cyber China: Reshaping National Identities in the Age of Information (pp. 19-36). Palgrave Macmillan.

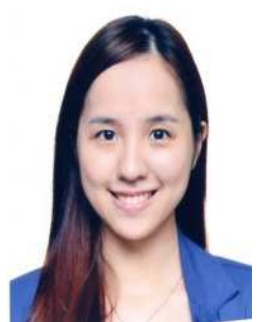

Wendy Chan Wing Lam is currently a Ph.D. student at the School of Communication at Hong Kong Baptist University. She completed her master degree in inter-cultural studies at the Chinese University of Hong Kong and attained her bachelor of arts degree in journalism and mass communication at Hong Kong Shue Yan University. She is interested in human communications online. She has a wide range of publication on exploration of social media and traditional media. 